\title{
DIFERENCIAÇÃO DOS PRODUTORES DE SOJA NO SUDESTE DE MATO GROSSO - BRASIL
}

\author{
VALDEMAR JOÃO WESZ JUNIOR ${ }^{1}$ \\ Universidade Federal Rural do Rio de Janeiro
}

Resumo: O objetivo deste artigo é analisar os diferentes perfis dos sojicultores no Sudeste de Mato Grosso (Brasil), explorando as lógicas de organização, os mecanismos de enraizamento local e as relações de troca construídas com as empresas. Para tanto, conciliou-se um amplo conjunto de técnicas de pesquisa de natureza qualitativa e quantitativa, como revisão bibliográfica, análise estatística, entrevistas semiestruturadas e observação participante. Apesar de a tipologia ser construída sob diferentes variáveis, os formatos das relações de troca com as empresas e as modalidades de negócio acabaram sendo o eixo central para distinguir os produtores. Seguindo essa orientação, foram encontrados cinco perfis de sojicultores na região em destaque, que apresenta uma grande diversidade de situações.

Palavras-chave: Produtores de Soja; Mato Grosso; Agronegócio.

\section{DIFFERENTIATIONOFSOYBEANPRODUCERS IN SOUTHEASTOF MATO GROSSO - BRAZIL}

Abstract: The aim of this article is to analyze the different profiles of soy bean farmers in southeast Mato Grosso (Brazil), exploring their logics of organization, the mechanisms of local embeddedness and trade relationships between firms. To do this, a wide range of research techniques of qualitative and quantitative nature -literature review, statistical analysis, semi-structured interviews and participant observation - was employed. Al though the typology was built using different variables, the nature of trade relations between firms and the types of business activities ended up being the central criteria to distinguish the producers. Following this orientation, five profiles of soy bean farmers were identified in the highlighted area, comprising a wide variety of situations.

Keywords: Soybean Producers; Mato Grosso; Agribusiness.

\footnotetext{
${ }^{1}$ Doutor pelo Programa de Pós-Graduação de Ciências Sociais em Desenvolvimento, Agricultura e Sociedade na Universidade Federal Rural do Rio de Janeiro (CPDA/UFRRJ). Atualmente é professor adjunto na Universidade Federal da Integração Latino-Americana (UNILA) e pesquisador no Grupo de Estudos em Mudanças Sociais, Agronegócio e Políticas Públicas (GEMAP) e no Observatório de Políticas Públicas para Agricultura (OPPA). Contato: jwesz@yahoo.com.br.
} 


\section{Introdução}

O cultivo da soja ao longo da segunda metade do século XX apresentou um intenso processo de expansão no Brasil, que teve início no sul do país, seguiu para o Cerrado e hoje atinge parte do bioma amazônico. Atualmente, o complexo soja (grão, óleo e farelo) é considerado a principal atividade agropecuária do país, pela sua importância tanto territorial (30 milhões de hectares plantados em 2013/14, o que equivale a $53 \%$ dos cultivos temporários), quanto econômico-comercial (9,4\% das exportações totais de 2012) (CONAB, 2015; SECEX, 2014). Em paralelo, o Brasil se solidificou como o maior exportador mundial de soja em grão e pode se tornar o primeiro produtor nas próximas safras, superando os Estados Unidos (USDA, 2014).

Em Mato Grosso, principal estado brasileiro produtor de soja, tem havido crescimento na área plantada e na produção em paralelo à redução no número de produtores (CONAB, 2015; IBGE, 2012). Para as entidades de representação do setor o cultivo tem se concentrado nos sojicultores que possuem grande extensão fundiária, detém capital fixo para produção (maquinários, equipamentos e infraestrutura), fazem amplo uso das inovações tecnológicas e promovem a crescente informatização dos instrumentos de gestão (APROSOJA, 2011; SOUAGRO, 2011). A exclusão de muitos produtores da atividade teria ocorrido em meio às chamadas crises setoriais (marcadas pela queda nos preços, variabilidade climática, novas pragas, aumento do custo de produção, defasagem cambial, tensões ambientais etc.), o que os endividou, tendo como alternativa a venda ou arrendo de suas áreas.

Apesar desta concentração nos produtores mais capitalizados (em termos econômicos e financeiros), este estudo procura demonstrar que o cultivo da soja ainda hoje é permeado por uma ampla diversidade de tipos de produtores, inclusive nas "regiões modelo" do agronegócio brasileiro. Nessa direção, o objetivo deste trabalho é analisar os distintos perfis dos produtores de soja no Sudeste de Mato Grosso $^{2}$, explorando, em cada grupo, as lógicas de organização, os mecanismos de enraizamento local e as relações de troca construídas com empresas a montante e a jusante.

\footnotetext{
${ }^{2}$ A escolha da Mesorregião Sudeste Mato-Grossense está relacionada a quatro fatores principais: i) presença de uma importante e significativa produção de soja (IBGE, 2013), sendo a região precursora deste cultivo no Estado; ii) incidência de um conjunto diversificado de produtores rurais que plantam o grão; iii) presença de um grupo amplo de empresas envolvidas com o mercado da soja: esmagadoras, exportadoras, revendas de insumo, assistência técnica, usinas de biodiesel etc.; iv) contato prévio do pesquisador com moradores da região que conhecem técnicos e produtores, facilitando a entrada em campo e o desenvolvimento da pesquisa.
} 
Este trabalho concilia um amplo conjunto de técnicas de pesquisa de natureza qualitativa e quantitativa, como revisão bibliográfica, busca documental e análise estatística - sobretudo em cima dos Censos Agropecuários/IBGE (Instituto Brasileiro de Geografia e Estatística) ${ }^{3}$, PAM/IBGE (Produção Agrícola Municipal), Série Safras da Conab (Companhia Nacional de Abastecimento), Secex (Estatísticas do Comércio Exterior), IMEA (Instituto Mato-Grossense de Economia Agropecuária), dentre outros. Paralelamente, realizaram-se pesquisas de campo em 2012 e 2013, especialmente nos municípios de Campo Verde e Primavera do Leste, mas também em Rondonópolis, Poxoréu, Jaciara e Cuiabá. Foram feitas 36 entrevistas qualitativas, que possibilitaram o acesso a um conjunto amplo de atores, como produtores rurais, gerentes de fazenda, caminhoneiros, serviços terceirizados, representantes das empresas, o poder público, assistência técnica e organizações sindicais, associativas e cooperativas.

Dentre os produtores, procurou-se cobrir a maior diversidade de situações possível: diferentes condições fundiárias (vários tamanhos de área e com terras próprias e arrendadas), diversos graus de participação social (em cooperativas, sindicatos, movimentos sociais, partidos políticos etc.), variadas formas de comercialização (venda direta, contratos futuros, troca de grãos por insumos etc.), distintas origens (gaúchos, paulistas, paranaenses, argentinos, mato-grossense, catarinenses, rondonianos etc.), diferentes graus de diversificação do negócio (somente soja e milho, lavoura e pecuária, lavoura e atividades complementares etc.) e diversa infraestrutura na propriedade (desde quem terceiriza todo o processo produtivo até aqueles que possuem toda a estrutura no estabelecimento).

No que se refere às diferentes condições fundiárias, foram entrevistados desde grandes grupos, como o El Tejar e o Bom Futuro - que plantam mais de 200 mil hectares de soja em Mato Grosso (entre própria e arrendada) - até assentados da reforma agrária, que produzem o grão em 10 hectares.

Este artigo está estruturado em quatro seções, para além desta Introdução. A primeira apresenta a expansão do cultivo da soja em Mato Grosso, enquanto a segunda concentra-se na Mesorregião Sudeste - fazendo uma descrição geral dos sojicultores a partir dos microdados do Censo Agropecuário de 2006 (IBGE, 2012). Em seguida, analisam-se os distintos perfis dos produtores do grão, explorando cada grupo em separado. Por fim são retomadas algumas considerações sobre a diversidade de sojicultores na região selecionada.

\footnotetext{
${ }^{3}$ Em relação aos dados do último Censo Agropecuário 2006 (IBGE, 2012), iniciou-se com um levantamento das informações disponíveis no website do órgão, através do SIDRA (Banco de Dados Agregados). Como estas informações são de cunho mais geral também foram utilizados os microdados do Censo, que permitiram uma caracterização mais fina dos sojicultores mato-grossenses.
} 


\section{Expansão do cultivo da soja em Mato Grosso}

Ao longo dos anos a soja foi se expandindo em Mato Grosso e se tornou a principal atividade econômica, alcançando mais de 8 milhões de hectares plantados na safra 2013/14 e respondendo por 60\% do valor das exportações totais (CONAB, 2015; SECEX, 2014). Conforme Fernández (2007), a trajetória das lavouras de soja no estado está fortemente relacionada com a disponibilidade de grandes estoques de terras criada pela iniciativa estatal, pela presença de empresas de colonização privada ou ainda pela ação de agentes intermediários, como corretores e grileiros, que favoreceram a aquisição de grandes extensões de terras por emigrantes sulistas a preços relativamente baixos quando comparados com outros estados do Centro-Sul.

Vale destacar que trata-se de terras de planalto, com topografia plana que favorece o cultivo em larga escala; de latossolo, que, apesar da baixa fertilidade natural e da acidez, é profundo e bem drenado permitindo a mecanização; e que possui regularidade climática, com duas estações bem definidas, o que facilita o desenvolvimento dos ciclos produtivos. Também houve uma série de políticas públicas para a abertura de área, aquisição de máquinas, construção de infraestrutura (entre elas estradas, portos e cidades), investimentos em pesquisa, formação de mercados, assistência técnica etc. (FERNÁNDEZ, 2007; HEREDIA, PALMEIRA; LEITE, 2010; MORENO, 2005). Portanto, trata-se de um conjunto de condições e fatores que possibilitaram a expansão da soja em Mato Grosso, saindo dos argumentos mais usuais que se prendem especificamente à inovação tecnológica, especialização da produção, gestão e coordenação econômica, aumento do preço e da demanda etc. - ainda que os mesmos tenham sido importantes.

Até a metade da década de 1970, o plantio da soja era experimental e resultado de iniciativas individualizadas que foram realizadas em diferentes municípios do estado. Um dos produtores entrevistados, natural de Cruz Alta - RS, comprou uma propriedade de 15 mil hectares na região de Primavera do Leste em 1973 e declara: "o primeiro que plantou soja aqui [na região de Primavera do Leste] fui eu. Foi de 1976 para 1977. No início não produziu bem, não tinha variedade adaptada pro clima e pro tipo de terra daqui, mas depois foi aprimorando". Naquele período ainda havia barreiras que dificultavam e/ou impediam o plantio da soja, decorrentes da baixa fertilidade natural dos solos e da sua elevada acidez, além da ausência de variedades adequadas aos dias longos e de problemas de infraestrutura na produção e no escoamento.

Os dados da CONAB (2015) identificam a safra 1977/1978 como o começo do cultivo da soja em Mato Grosso, em uma área de mil hectares. No início de 1980 a oleaginosa teve o primeiro movimento de crescimento da área cultivada, chegando a mais de 300 mil ha (1983) (ver Figura 1). Conforme os dados da Produção 
Agrícola Municipal (IBGE, 2013), a principal região era o Sudeste MatoGrossense, que concentrava mais de $70 \%$ da área colhida deste estado.

Ao longo da década de 1980 começam a ser introduzidas novas variedades de soja, moldadas às condições edafoclimáticas do Cerrado; e também se alteram as formas de plantio e manejo dos solos, sobretudo com aplicação de calcário (BERNARDES, 2005). Além disso, até meados dos anos oitenta vigorava uma política de crédito rural altamente subsidiada, que se voltava ao financiamento de custeio, investimento e comercialização da produção (LEITE, 1998). Também foi importante a retomada do preço internacional da soja a partir da segunda metade daquela década e a substituição do consumo de gorduras animais (banha e manteiga) por óleos vegetais, estrategicamente elaboradas pelas empresas do setor (WESZ JR., 2011). Esses elementos foram centrais para a expansão da área cultivada, que chegou a 1,7 milhão de hectares em 1989; bem como para o aumento da produção e da produtividade (que nesta década saltou de 30 para 40 sacas/ha).

Esses processos simultâneos e inter-relacionados favoreceram o avanço das lavouras de soja para duas novas regiões do estado: a Microrregião de Parecis, próxima à fronteira com Rondônia, onde se destacam os municípios de Sapezal, Campos de Julio, Diamantino e Campo Novo dos Parecis; e a Microrregião de Alto Teles Pires, localizada ao longo da BR-163, abrangendo principalmente os municípios de Sorriso, Lucas do Rio Verde, Nobres e Nova Mutum, que foram alvo de diversos projetos de colonização. Essas duas microrregiões passaram a responder pela metade da superfície colhida no estado, que, se somada aos valores da mesorregião Sudeste, alcançavam 85\% da área em 1989 (IBGE, 2013). Na década de 1980 o Mato Grosso se tornou o terceiro maior estado produtor de soja, atrás do Paraná e do Rio Grande do Sul. Outro marco deste período foi a superação da área colhida com arroz, que até então era o principal cultivo temporário.

A década de 1990 se inicia com a primeira redução na área e na produção de soja em Mato Grosso, seguindo a tendência nacional de baixa devido, fundamentalmente, à forte queda no preço internacional. Mas na safra 1995/96 começa um processo de recuperação, com um crescimento praticamente ininterrupto da área cultivada até 2005/06, que alcança mais de seis milhões de hectares. Portanto, em dez anos a superfície cultivada com soja foi triplicada (Figura 1). Além do aumento da demanda e do preço internacional, foi fundamental para esta expansão a mudança da política econômica, que desvalorizou o câmbio e reeditou a política de geração de saldos comerciais ancorados na exportação de produtos primários.

Com a redução do preço da soja, deixam de ser cultivados dois milhões de hectares de 2006 a 2007. Entretanto, nas safras seguintes há uma nova retomada, alcançando 26,5 milhões de toneladas e 8,6 milhões de hectares - crescimento de $72 \%$ e 68\%, respectivamente, de 2006/07 a 2013/14 (Figura 1). Neste intervalo de sete safras o preço da soja alcançou recordes históricos e a demanda internacional 
cresceu a passos largos. Também foram fundamentais para tal avanço as inovações tecnológicas (sementes melhoradas, plantio de precisão, novos insumos etc.) e a conversão das áreas de pastagens ou mata em lavouras temporárias.

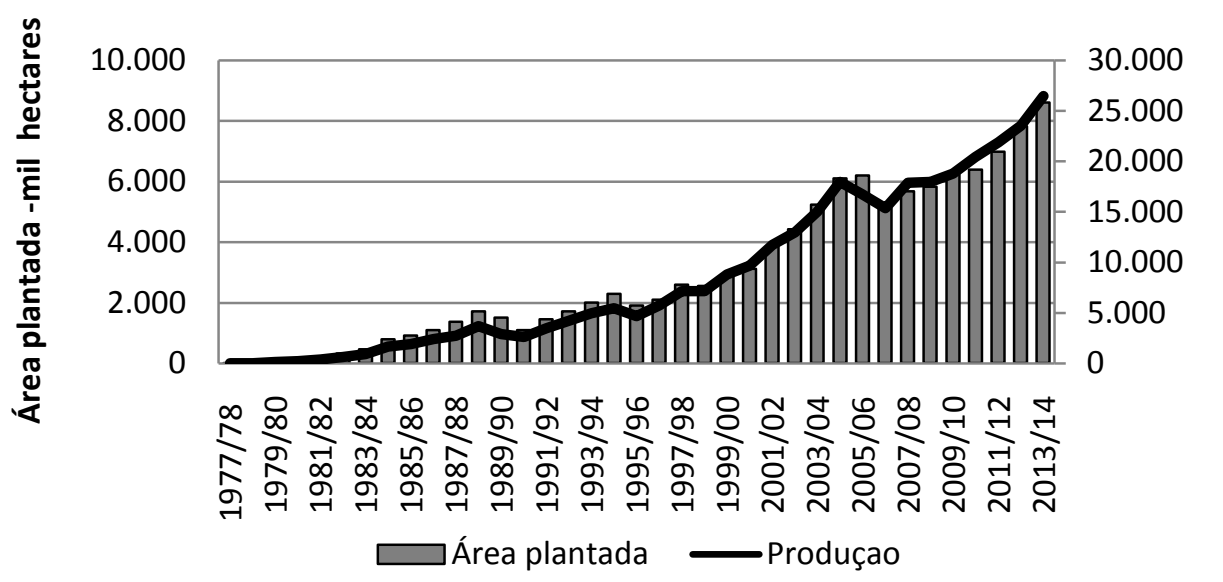

Figura 1: Área plantada e produção de soja em Mato Grosso (safra 1977/78 - 2013/14). Fonte: CONAB (2015).

Como já comentado, a produção de soja teve início no Sudeste Mato-Grossense e os anos 1980 difundiu-se para o centro-norte do estado, consolidando na década de 1990 três grandes manchas de produção: Parecis, BR-163 e Sudeste. Conforme a Figura 2, de 2000 a 2010 ocorre um aumento das áreas com produção, que inclui tanto as regiões acima mencionadas (com expansão na direção norte) como a ampliação para novas áreas, com destaque ao Vale do Araguaia, que segue a BR158, na fronteira com Goiás e Tocantins. A partir dos mapas abaixo, pode-se dizer que somente no Pantanal e na Depressão da Amazônia Meridional (noroeste do estado) o cultivo do grão não está presente de modo significativo. 

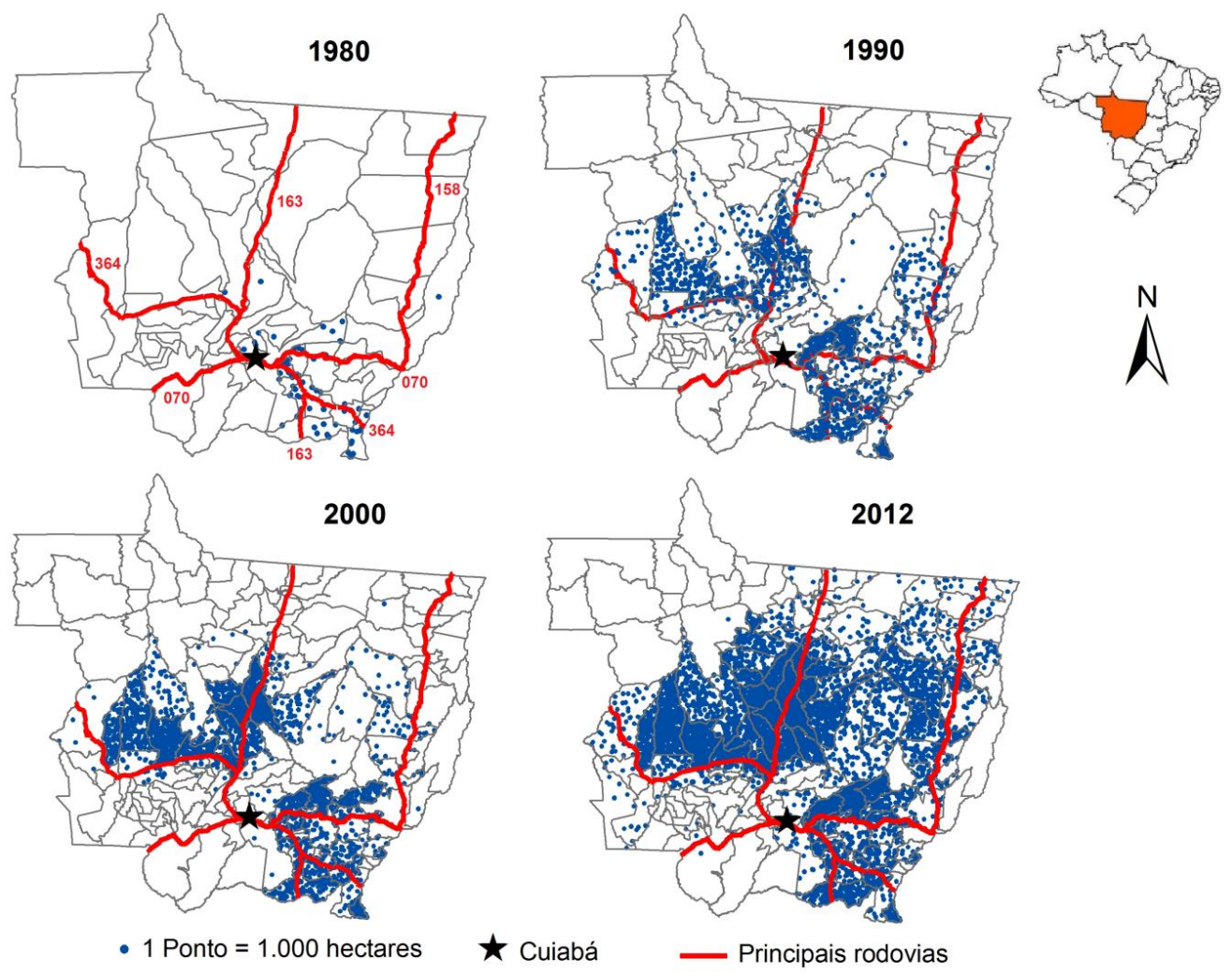

Figura 2: Área colhida com soja por município em Mato Grosso (1980 - 2012).

Fonte: Pesquisa Agrícola Municipal (IBGE, 2013). Elaboração do autor.

\section{A Mesorregião Sudeste de Mato Grosso e os produtores de soja}

A Mesorregião Sudeste do Mato Grosso é composta por quatro microrregiões (Alto Araguaia, Primavera do Leste, Rondonópolis e Tesouro) e 22 municípios (ver Figura 3). Na década de 1940 havia apenas três localidades emancipadas: Alto Araguaia, Lajeado (que em 1943 mudou de nome para Guiratinga) e Poxoréu. Naquele período a população era de 41.623 pessoas, sendo que praticamente $80 \%$ moravam no meio rural. Após um intenso processo de migrações, que teve o seu auge na década de 1970, o número de moradores ampliou-se significativamente, aproximando-se em 2010 das 400 mil pessoas - sendo que 50\% vivem em 
Rondonópolis (centro urbano-agroindustrial ${ }^{4}$ ). A população rural, que em 1970 chegava a 100 mil habitantes, teve uma redução superior a 50\% nos últimos anos, alcançando 46.610 em 2010 (o que representa 12\% do total) (IBGE, 2014).

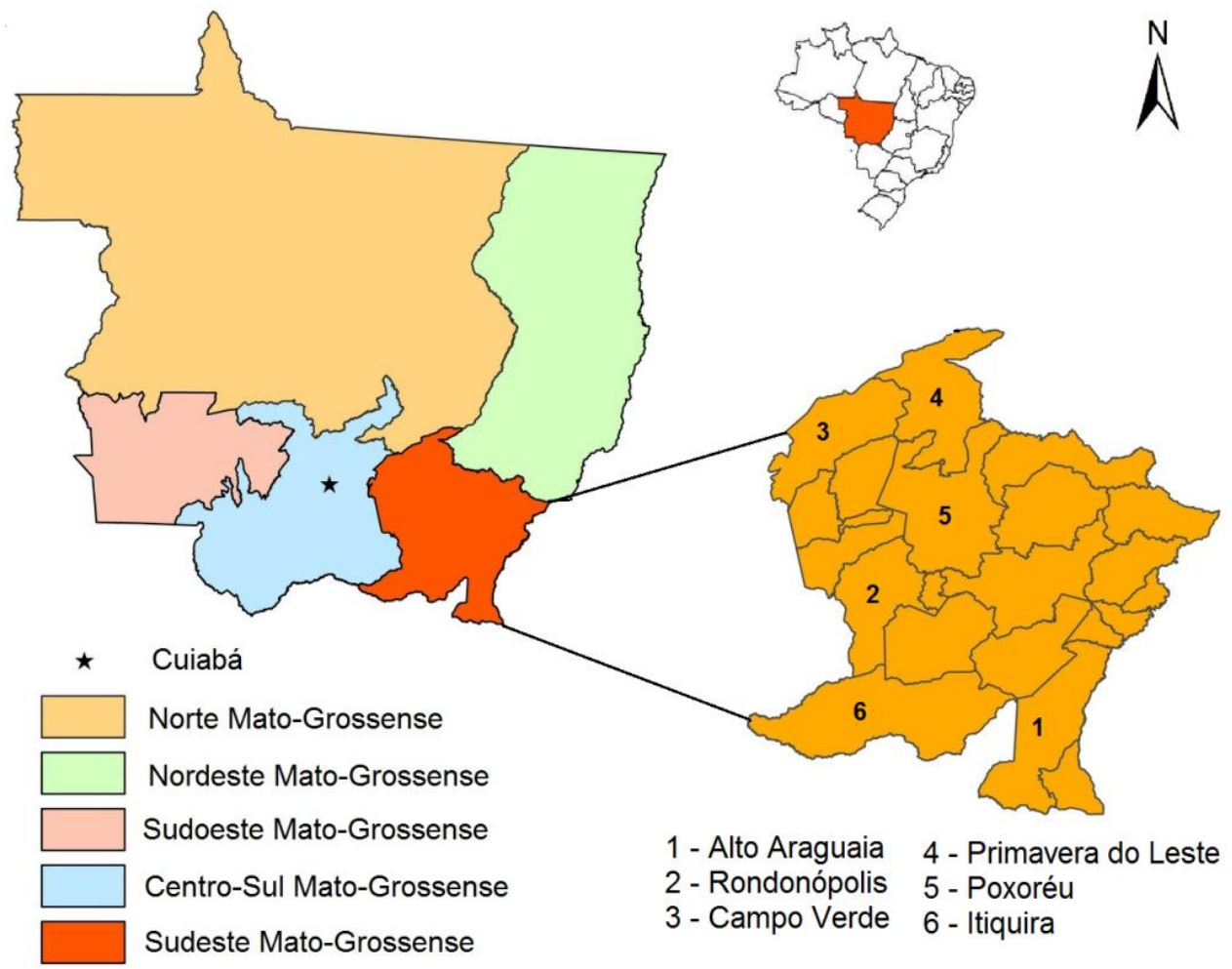

Figura 3: Mato Grosso e a Mesorregião Sudeste Mato-Grossense.

Fonte: IBGE (2014). Elaboração do autor.

O número de estabelecimentos agropecuários apresentou uma grande ampliação entre 1940 e 1970, saindo de 772 para 13.867. Entretanto, nos anos posteriores ocorreu uma queda expressiva, chegando a 10.972 em 2006. Essa redução teria sido maior se não fossem os vários assentamentos rurais criados na região recentemente, que hoje representam em torno de dois mil estabelecimentos $(16 \%$ do total). Mesmo com os assentamentos há uma elevada concentração fundiária, visto que as unidades com mais de dois mil hectares dominam, em 2006, mais de $50 \%$ da área total (esse valor chega a $85 \%$ se consideradas todas as unidades acima de 500 hectares) (IBGE, 2012).

\footnotetext{
${ }^{4}$ Neste município se encontram os principais serviços urbanos regionais (centros de saúde, educação etc.) e concentra-se uma parte expressiva das agroindústrias do Mato Grosso (50\% das indústrias de fertilizantes, $44 \%$ das sementeiras e mais de um terço da capacidade de esmagamento de soja) (WESZ JR., 2014).
} 
Entre a década de 1970 e 1980 o cultivo predominante era o arroz, seguido pelo milho, feijão e mandioca - período em que a soja começa a entrar na região. As principais criações eram a bovinocultura de corte (com mais de um milhão de cabeças) e a suinocultura (com cem mil animais). Na década de 1990 o arroz, o feijão e a mandioca perdem expressividade e a soja passa a dominar a maior parte da área com lavouras temporárias. Nos anos 2000 a oleaginosa consolida-se como principal atividade agropecuária (IBGE, 2013).

Assim como no restante do estado, parte significativa da produção de soja está vinculada às propriedades que detém grandes extensões de área cultivada. Como pode ser visualizado na Figura 4, 75\% da oleaginosa plantada em 1996 estava em estabelecimentos com área superior a mil hectares, enquanto que os estratos com extensões abaixo de 500 ha respondiam por apenas 8,5\%. Em 2006 houve uma expressiva ampliação da produção em estabelecimentos com área total superior a mil hectares, que alcançou praticamente $90 \%$ do total cultivado com o grão (IBGE, 2012). Esse cenário mostra que o cultivo da oleaginosa na região Sudeste do estado tem se direcionado para os estabelecimentos maiores, embora os menores e medianos mantenham sua presença. Na região em análise a agricultura familiar ${ }^{5}$ responde por $10,3 \%$ do número de estabelecimentos produtores de soja, mas por menos de $1 \%$ da quantidade produzida, área colhida e valor da produção.

\section{6}

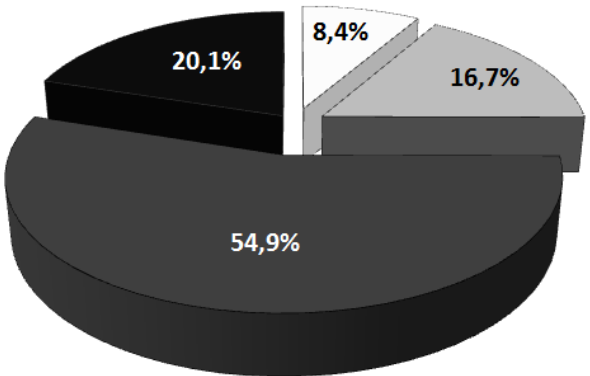

Até 500 ha
De 500 a 1.000

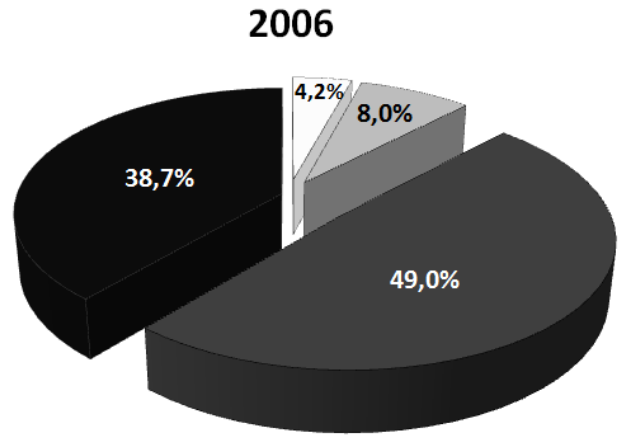

De 1.000 a 5.000
Acima de 5.000

Figura 4: Produção de soja por estratos de área total nos estabelecimentos agropecuários da Mesorregião Sudeste Mato-Grossense (1996 e 2006).

Fonte: Censos Agropecuários (IBGE, 2012).

\footnotetext{
${ }^{5}$ O Censo Agropecuário de 2006 classifica a agricultura familiar segundo a definição oferecida pela Lei $\mathrm{n}^{\circ}$ 11.326. Por esta fonte, são considerados agricultores familiares aqueles que cumprem, simultaneamente, os seguintes critérios: utilizam predominantemente mão de obra da própria família; têm renda familiar predominantemente originada de atividades econômicas vinculadas ao próprio estabelecimento; dirigem o estabelecimento com auxílio de pessoas da família; não possuem área superior a quatro módulos fiscais (como essa unidade de medida varia entre os municípios, a superfície máxima permitida para enquadramento oscila entre 20 e 440 hectares).
} 
Os microdados do Censo Agropecuário de 2006 (IBGE, 2012) permitem a identificação de algumas características dos produtores de soja desta região: são majoritariamente proprietários $(81,3 \%)$; residentes no próprio estabelecimento ou na sede urbana do município (82,8\%); com supremacia masculina na direção das unidades produtivas $(97,4 \%)$; idade superior a 40 anos (72\%); nível de instrução maior que a média estadual (mais de $20 \%$ tem ensino superior); realizam a gestão das suas atividades de modo familiar (apenas $18 \%$ não utilizam mão de obra familiar no estabelecimento). Além disso, possuem um elevado grau de cobertura tecnológica (agrotóxicos, adubação química, plantio direto, correção do solo etc.) e de máquinas (trator, pulverizador, colheitadeira etc.). Outro dado importante é que quase $30 \%$ dos sojicultores têm silos dentro da propriedade, com condições de armazenar até $55,5 \%$ da produção de soja colhida no Sudeste Mato-Grossense. Outro dado que o Censo permite verificar é a baixa diversificação dos produtores de soja, pois apenas $53,8 \%$ cultivam milho, $12,2 \%$ algodão, $2,5 \%$ feijão e $1,5 \%$ mandioca.

Em suma, os microdados do Censo Agropecuário nos oferecem uma perspectiva geral sobre as características dos produtores e do sistema de produção. Contudo, essas informações não permitem explorar com maiores detalhes as lógicas de organização, a trajetória familiar, os mecanismos de enraizamento local etc. Nesse sentido, foi construída uma tipologia a partir da pesquisa de campo que é mais precisa e atualizada.

\section{Os perfis dos sojicultores no Sudeste Mato-Grossense ${ }^{6}$}

Durante a pesquisa de campo ficou evidente a presença de uma grande heterogeneidade de sojicultores no Sudeste de Mato Grosso. Para compreender de forma mais profunda essa diversidade, optou-se por construir uma tipologia para estes produtores, seguindo algumas orientações já apresentadas por diferentes pesquisadores para o Cone Sul (ARBELETCHE; CARBALLO, 2006; PÉREZ LUNA, 2007; GROSSO et al., 2010; OYHANTÇABAL; NARBONDO, 2011; URIOESTE, 2011; AMEGHINO, 2012; GRAS, 2012; 2013; GUIBERT; BUHLER, 2013), que se afastam da simples consideração de pequenos, médios e grandes produtores - classificação pautada exclusivamente no tamanho da área dos estabelecimentos. Nesta pesquisa a tipologia foi construída sob diferentes variáveis: dimensão fundiária, lógicas de organização, infraestrutura, dinâmicas de acumulação, origem socioespacial, grau de diversificação das atividades produtivas e dimensão econômica.

Apesar de incorporar estas diversas dimensões e variáveis na construção da tipologia, os formatos das relações de troca com as empresas e as modalidades de

\footnotetext{
${ }^{6}$ Para um aprofundamento desta discussão, consultar Wesz Jr. (2014).
} 
negócio acabaram sendo o eixo central para distinguir os produtores. Caso o objetivo fosse diferenciar os sojicultores por padrão tecnológico, forma de gestão, escala de produção ou capacidade financeira, por exemplo, a tipologia teria um desenho diferenciado. Além disso, deve-se reiterar que este exercício foi desenvolvido a partir dos produtores encontrados na Mesorregião Sudeste de Mato Grosso e haveria contornos diferenciados caso a abrangência geográfica fosse alterada.

Seguindo essa orientação, foram encontrados cinco perfis de sojicultores ${ }^{7}$ na Mesorregião Sudeste de Mato Grosso, a saber: i) os grandes grupos familiares, cuja compra de insumos e venda da soja são efetivadas diretamente com as firmas transnacionais; ii) o grupo empresarial, que realiza a maior parte dos seus negócios em uma escala supranacional; iii) os médios produtores rurais, cujas relações de troca estão baseadas em diferentes empresas (firmas transnacionais, revendas locais, exportação direta etc.), sendo que a variação está atrelada, principalmente, ao fato de atuar de forma individual ou coletiva; iv) os pequenos produtores rurais, cuja relação baseia-se predominantemente em revendas locais e empresas menores (sobretudo de capital nacional); e v) os assentados da Reforma Agrária, com troca intermediada, principalmente, pelo Programa Nacional de Produção e Uso do Biodiesel (PNPB). Abaixo são descritas as características de cada grupo, com especial atenção ao formato das relações de troca com as empresas e às modalidades de negócio.

\section{Grandes grupos familiares}

Na Região Sudeste de Mato Grosso tem aumentado o número de produtores rurais organizados em grupos para desenvolver as atividades agrícolas, os quais mantêm, predominantemente, a propriedade entre os membros da família (irmãos ou pai e filhos), não havendo a presença de sócios que não pertençam ao núcleo familiar. Dentro deste perfil de produtor houve nos últimos anos uma crescente profissionalização das decisões mais específicas (calendários produtivos, organização do trabalho etc.), que passam a ser delegadas a assessores técnicos ou administradores a partir do processo de expansão dos negócios. Apesar disso, a família mantém-se enquanto ator central nas decisões mais estratégicas, como investimentos futuros, incorporação de novas tecnologias e áreas, compra de insumos, venda da produção etc. O Grupo Bom Futuro, por exemplo, que foi considerado o maior produtor mundial de grãos (EXAME, 2013), é constituído por

\footnotetext{
${ }^{7}$ A denominação de cada perfil destaca alguns elementos em particular, como a forma de gestão, a dimensão fundiária e o modo de acesso a terra. Contudo, existem outros tantos elementos que os caracterizam para além da sua estrita denominação. Apesar disso, mantiveram-se estas identificações para não usar nomes aleatórios que se desvinculem de algum predicado particular (ex.: Tipo 1, Tipo 2 etc.).
} 
três irmãos e um cunhado. Embora exista uma estrutura organizacional bem definida (Administrativo, Comercial, Técnico etc.), a maior parte das decisões é conduzida diretamente pela família, sem passar pelos conselhos e setores respectivos.

O Grupo Bom Futuro é uma empresa familiar e por isso não é tão formal quanto se parece nos desenhos da estrutura organizacional (...). Em termos de mando, as fazendas estão ligadas diretamente aos diretores. Os donos da Bom Futuro não são pessoas distantes do negócio, são pessoas presentes. O Zeca [um dos sócios] mesmo vive rodando pelas propriedades e fala direto com os gerentes das fazendas (Entrevista ao Grupo Bom Futuro).

Este perfil caracteriza-se pela grande extensão fundiária (mais de 20 mil hectares), composta principalmente por áreas próprias, ainda que estas sejam complementadas com terras arrendadas. Geralmente as áreas não estão centradas em apenas um município ou região, encontrando-se distribuídas em outras localidades e, em alguns casos, fora do estado. Além disso, há um reduzido grau de terceirização das atividades produtivas, uma vez que possuem todos os maquinários necessários (tratores, colheitadeiras, semeadeiras, pulverizadores etc.) e infraestrutura própria (armazéns, silos, balança, secador etc.). É corriqueiro encontrar atividades complementares à agricultura, como pecuária, algodoeira (indústria de processamento de algodão), armazenagem, serviços de aviação agrícola e produção de sementes.

Alguns grupos com maior poder econômico ainda investem em empresas de energia por meio de hidrelétricas, escoamento da produção para terceiros, revenda de insumos, de máquinas e equipamentos, prestação de assistência técnica, indústria de biodiesel etc. Nesse sentido, trata-se de ramos que auxiliam diretamente a produção agrícola, reduzindo a dependência de terceiros ao longo da cadeia produtiva e ampliando sua competitividade no setor. Em suma, são atores que desenvolveram, de forma paralela, lógicas pluriterritoriais e transetoriais ${ }^{8}$, pois atuam em diferentes regiões e em ramos complementares à agricultura stricto sensu.

Não obstante a crescente inserção nos mercados globais e a sua maior profissionalização, estes grandes grupos mantêm a gestão familiar e seu vínculo muito próximo com os diferentes territórios em que estão presentes. Nessa direção, há um forte envolvimento com o tecido social, em que os coordenadores têm uma participação ativa nos eventos locais (festas, bailes, feiras etc.). Também estampam as revistas locais sobre empreendedorismo, profissionais de sucesso, melhor empresa do ano (chamado na região de Oscar Empresarial) etc. Muitos ainda

\footnotetext{
${ }^{8}$ Um processo semelhante foi visualizado por Hernández, Muzi e Riglos (2013) na Argentina.
} 
mantêm uma relação direta com a política, seja como apoiadores de determinado partido ou como candidatos a prefeito, deputado ou governador. $\mathrm{O}$ principal exemplo é Blairo Maggi (Grupo Amaggi), que foi governador do estado por dois mandatos e atualmente é senador.

No que se refere às relações de negócio, os grandes grupos familiares compram insumos diretamente das companhias transnacionais via Representante Técnico de Venda (RTV) e não adquirem estes produtos nas revendas ou cooperativas locais (somente em casos emergenciais). Assim, a aquisição de sementes e defensivos é feita diretamente nas empresas produtoras (Monsanto, Basf, Dupont, Syngenta, Bayer, Dow etc.) que dispõem de RTVs na região. A maior parte da venda da soja é feita previamente, antes mesmo do plantio da oleaginosa, geralmente com preço pré-fixado em dólar. $\mathrm{O}$ destino da produção envolve as grandes empresas transnacionais que atuam na região (Bunge, Cargill, ADM, Dreyfus, Amaggi e Noble), de onde geralmente é oriunda parte do financiamento ${ }^{9}$ e da adubação. $\mathrm{O}$ grande volume adquirido e a eliminação dos intermediários, além da fidelidade para com a empresa, lhes garantem um "preço mais em conta", conforme comentou um dos entrevistados.

\section{Grupo empresarial}

Optou-se por diferenciar o grupo empresarial (baseando-se no caso do El $\operatorname{Tejar}^{10}$ ) dos grupos de gestão familiar, pois existem variações importantes, apesar de ambos terem controle de grandes extensões de terra, elevada escala de produção e constantes inovações tecnológicas. El Tejar é de origem argentina e passou a arrendar terras em Mato Grosso em 2003. Apesar da sua lógica de produção estar baseada no arrendamento da terra (GUIBERT et. al., 2011; GRAS, 2013), em 2007 a firma aproveitou a situação de endividamento de alguns produtores para comprar grandes áreas (58 mil hectares), cuja fonte de recursos foi a venda de parte de suas ações para fundos de investimento. A área plantada com soja chegou a 216 mil hectares na safra 2011/12.

Diferentemente do esquema usual de arrendamento (em que apenas a terra é alugada), El Tejar trabalha na região com uma forma distinta, que por eles é chamada de parceria. Nesse caso a empresa faz um "arrendamento de porteiras fechadas", que inclui a terra, os maquinários, a infraestrutura e a mão de obra dos

\footnotetext{
${ }^{9}$ Vale destacar que estes grandes grupos familiares localizados no Sudeste Mato-Grossense não acessam diretamente o mercado financeiro e os recursos externos, nem abriram seu capital na bolsa de valores, como ocorre com os produtores empresariais que serão apresentados a seguir. Nesse grupo o crédito é acessado localmente por meio de intermediários, e estes sim estão articulados com suas matrizes que, por sua vez, recorrem ao mercado financeiro internacional (como é o caso dos recursos acessados via trading).

${ }^{10}$ El Tejar é o único produtor de soja que se identificou neste perfil e que atua no Sudeste de Mato Grosso.
} 
proprietários. El Tejar oferece os insumos e as orientações técnicas e o proprietário cultiva a sua área com os seus maquinários, realizando plantio, manejo e colheita. Deste modo, os produtores que arrendam suas terras -localmente chamados de peão de argentino - tornaram-se prestadores de serviço mesmo sendo proprietários dos meios de produção.

Uma das diferenças entre os grupos de gestão familiar e o grupo empresarial é que no primeiro caso permanece a consonância entre propriedade da terra e desenvolvimento da produção, enquanto no segundo o arrendamento da terra é majoritário, apesar do investimento mais recentemente na compra deste ativo. Portanto, a existência de capital fixo é reduzida e praticamente todas as etapas da produção são terceirizadas. Além disso, é evidente uma gestão financeira, econômica, comercial e agronômica muito profissional, preocupada com a mitigação do risco de produção e comercial (GRAS, 2012; GUIBERT et al., 2011; GROSSO et al., 2010). "A dinâmica que a gente tem é devido à gestão empresarial. Nas outras grandes empresas familiares essa dinâmica pode existir, mas não é tão agressiva" (Entrevista com El Tejar).

Um elemento interessante é que El Tejar possui uma atuação supranacional (produz de forma concomitante no Brasil, Argentina, Uruguai e na Bolívia), apresentando uma forte amplitude geográfica que diversifica os riscos climáticos e encontra melhores oportunidades de produção e comercialização. Outra diferença em relação ao primeiro grupo é que El Tejar praticamente não mantém um grau de sociabilidade e enraizamento nos municípios. Dessa maneira, não participam dos eventos locais, não há a imagem de um representante que circula na mídia, a sede administrativa do grupo é muito discreta - de modo que as pessoas que vivem na região desconhecem outras informações sobre área, produção etc. (situação bastante diferenciada da primeira tipologia apresentada).

Desde que chegou ao Brasil, El Tejar compra os insumos de apenas duas empresas: Monsanto e Basf. Como alertado por Guibert et al. (2011), a aquisição ocorre de maneira centralizada (inclusive com importações diretas), não passando pelos circuitos econômicos locais, salvo eventualidades. É importante destacar que esse relacionamento já ocorria na Argentina e foi conservado nos outros países em que El Tejar atua. Segundo o entrevistado, os principais fatores que favorecem a manutenção da negociação dizem respeito ao baixo preço final dos insumos, à presença de produtos conhecidos e de qualidade e à oferta de assistência técnica. É interessante perceber que mesmo produzindo soja em quatro países diferentes e em mais de 600 mil hectares eles conseguem manter a oferta de insumo vinculada a apenas duas grandes empresas transnacionais.

No que se refere ao comércio da soja, no mínimo $80 \%$ das vendas são feitas antes do início da safra, com preço pré e pós-fixado a depender das condições e perspectivas do mercado. Parte do grão é vendida para as grandes empresas transnacionais que atuam na região de cultivo (Bunge, Cargill, ADM, Amaggi) e parte é destinada diretamente à exportação (El Tejar possui uma firma específica 
para isso), assim como ocorre nos outros países onde o grupo atua. Em suma, grande parte das relações mercantis acontece em uma escala supranacional com firmas transnacionais, sendo que seu sistema de produção agrária é dinamizado por capitais externos ao empreendimento (capital financeiro). Assim, trata-se de atores que atuam com uma extensão geográfica bastante ampla (BÜHLER; OLIVEIRA, 2012).

\section{Médios produtores rurais}

Uma das características dos médios sojicultores é o elevado domínio fundiário, que geralmente vai de mil a dez mil hectares de área total ${ }^{11}$. Todos os entrevistados deste grupo afirmaram que compraram novas terras nos últimos dez anos, ampliando sempre que possível a área total desde a sua chegada à região (o que indica sua crescente capitalização). Estes produtores possuem boa infraestrutura de máquinas e equipamentos, como plantadeiras, colheitadeiras e pulverizadores - e alguns ainda contam com caminhões próprios e armazéns/silos. Um elemento comum é o elevado investimento em inovações tecnológicas, como o uso de sementes melhoradas, adubos e agroquímicos específicos, plantio direto e, mais recentemente, plantio de precisão. Assim como nos grandes grupos de gestão familiar, a preparação do solo, o plantio, manejo e colheita não são terceirizados, somente em casos excepcionais.

Em relação às formas de organização os médios produtores também possuem uma gestão familiar, geralmente entre irmãos, cunhados, tios e sobrinhos ou entre pai e filhos. Em paralelo, tem sido crescente a participação em cooperativas de produção e também sua articulação em sindicatos e associações, inclusive atuando ativamente na direção destas organizações em nível local e estadual. Tais produtores são conhecidos pela população local e alguns mantêm um envolvimento com a política municipal (prefeitos, vereadores, presidentes de partidos etc.).

De um modo geral, as principais diferenças entre os grandes grupos familiares e os médios produtores dizem respeito à escala produtiva, ao formato da gestão (que é menos setorizada e profissionalizada no segundo grupo) e à amplitude geográfica das suas áreas (visto que os médios produtores tendem a ter suas atividades mais concentradas em uma única região), além do formato das relações de troca com as empresas a montante e a jusante. Nos demais aspectos o que se percebe é uma grande semelhança: presença majoritária da propriedade da terra, trajetória familiar na agricultura, forte adaptabilidade às inovações tecnológicas, existência de capital

\footnotetext{
${ }^{11}$ A categoria "médios produtores" esteve presente em várias falas dos entrevistados durante as duas pesquisas de campo no Sudeste Mato-Grossense, sendo geralmente utilizada para referir-se àqueles sojicultores que possuem entre mil e dez mil hectares de área total. Como se trata de uma denominação presente na região pesquisada, optou-se por mantê-la, acrescida de outras características que serão apresentadas ao longo deste perfil.
} 
fixo, baixa utilização de serviços terceirizados, gestão familiar e envolvimento com o tecido social e político local/regional.

As relações de troca entre os produtores médios e as empresas variam, sobretudo entre aqueles que atuam em cooperativa e os que atuam de forma individual/grupo familiar. No caso dos cooperados a compra de insumos e a venda da soja geralmente são organizadas pela própria entidade, que é a responsável por enviar às firmas o volume demandado e define com quem serão estabelecidas as negociações a partir da melhor opção de preço. Portanto, a cooperativa tornou-se uma intermediária entre produtor e empresa, cujo principal benefício ao sojicultor é o menor custo na compra de insumos e a maior margem de rentabilidade na venda da produção (na qual a diferença pode alcançar $30 \%$ em relação à negociação conduzida de maneira individual).

Já os médios produtores individuais acabam fazendo praticamente todos os seus negócios de compra de insumos (adubos, semente, herbicidas e inseticidas) nas revendedoras locais, que organizam um pacote de produtos e serviços. Esse pacote inclui a venda de insumos e a assistência técnica, que serão pagos com a soja colhida. A outra parte da produção é vendida para as grandes empresas que atuam regionalmente (Bunge, Cargill, ADM, Amaggi, Dreyfus e Noble), geralmente com preço pré-fixado.

\section{Pequenos produtores rurais}

Este estrato refere-se fundamentalmente àqueles produtores com menos de mil hectares, cuja gestão e trabalho são familiares e o local de residência é o próprio estabelecimento agropecuário. Localmente afirma-se que este público "tem seus dias contados", no sentido de que não resistirão ao futuro próximo e que a opção possível é vender a área para produtores maiores ou comprar novas terras para se manter na atividade, dada a necessidade de um crescente ganho de escala para obter rentabilidade. Apesar da profecia regional e de ter havido redução de uma parcela importante nos últimos dez anos, este grupo tem se mantido na produção de soja.

Não obstante a sua manutenção na atividade agrícola, visualizada na pesquisa de campo e reconhecida pelos dados do Censo Agropecuário de 2006, estes produtores com menos ativos fundiários são praticamente invisíveis localmente. $\mathrm{O}$ fato de haver um discurso na região de que é impossível cultivar soja em área inferior a 500 hectares reforça e ao mesmo tempo condiciona esta invisibilidade. Portanto, é uma situação inversa ao que ocorre com os grandes grupos familiares e os médios produtores, que são conhecidos e reconhecidos localmente. Em alguns casos essa invisibilidade ocorre na própria entidade de representação, uma vez que os Sindicatos dos Trabalhadores Rurais atuam basicamente com os assentados da reforma agrária envolvidos na produção de soja para biodiesel; enquanto o 
Sindicato Rural Patronal tem como público majoritário os produtores com área superior a mil hectares. De um modo geral é um estrato que fica mais submisso ao poder das empresas.

A maior parte desses produtores atua de forma individual e são raros aqueles que estão associados às cooperativas, embora alguns participem de pequenas associações que exercem pouca interferência nas relações de troca (diferentemente do que foi visto com os médios produtores). Como não possuem recursos próprios para a compra de insumos, acabam fazendo os pacotes com as revendas para o cultivo da produção. É interessante perceber que com a criação das cooperativas pelos médios sojicultores os pequenos produtores e os assentados da reforma agrária acabaram se tornando um importante nicho a ser coberto pelas revendas. É importante dizer que estas firmas usam diferentes estratégias para atrair os produtores (dias de campo, feiras, churrasco, pescaria etc.), o que condiciona a compra de todos os insumos e a assistência técnica à mesma firma (ALMEIDA, 2013).

Grande parte da venda da soja não segue para as maiores tradings (Bunge, Cargill, ADM, Amaggi, Noble e Dreyfus) como nos casos acima descritos. Os principais argumentos presentes nas entrevistas são os de que "lá produtor pequeno não tem vez", "em multinacional não se sabe quem é o gerente", "a gente nunca vê o dono" e "só dão bola pros produtor grande". Os próprios entrevistados da BRF e da Cargill confirmaram esse interesse das firmas maiores em comprar a soja dos grandes e médios produtores, que produzem mais e já têm um histórico de relacionamento ao longo dos anos. Assim, o principal destino da soja dos pequenos agricultores são as firmas menores - como a Ovetril, Caramuru, Multigrain e CGG Trading - ou as próprias revendas de insumos que possuem armazéns na região.

\section{Assentados da Reforma Agrária}

De 1979 a 2011 foram criados 63 assentamentos rurais no Sudeste de Mato Grosso abrigando mais de 100 mil famílias, principalmente nos municípios de Campo Verde (19\%), Rondonópolis (15,8\%) e Poxoréu (12,9\%) (DATALUTA, 2012). Uma das características dos assentados é a sua diversidade de origem, pois advêm de diferentes estados. Nesse quesito tal segmento se difere dos outros perfis de produtores destacados neste trabalho, principalmente os dos grandes grupos familiares e dos médios produtores rurais, que são majoritariamente do Sul do país. Uma marca comum tanto nos novos como nos velhos assentamentos é a manutenção do local de moradia na sede do próprio lote. Esse grupo de produtores é representado pelo Sindicato dos Trabalhadores Rurais (STR) e com frequência organiza-se em associações e/ou pequenas cooperativas.

No município de Campo Verde, onde houve um contato maior com os assentados durante a pesquisa de campo, o tamanho dos lotes vai de 10 a 30 
hectares com uma variação que ocorre conforme $o$ ano de fundação do assentamento (quanto mais antigo, maior a área) e a qualidade das terras (quanto mais fértil e plana, menor o lote). Os assentamentos mais recentes, como é o caso do Dom Osório, possuem pouca ou nenhuma máquina agrícola e o acesso às políticas públicas de crédito rural e assistência técnica é praticamente inexistente. Por isso quase todas as etapas produtivas são terceirizadas por empresas externas ao assentamento - embora existam alguns poucos casos em que assentados mais estruturados tenham comprado uma plantadeira e cultivem o seu próprio lote e os dos vizinhos. Já no Assentamento 28 de outubro, que foi fundado em 1996, há produtores que tiveram acesso ao Pronaf e atualmente possuem maquinários próprios. Contudo, é corriqueiro encontrar assentados que arrendam áreas de outros, ampliando assim sua extensão cultivada. Um dos entrevistados, por exemplo, recebeu um lote de 25 hectares e depois comprou outro lote do mesmo tamanho. Além disso, arrenda outros dez lotes, plantando um total de 300 hectares de soja na safra 2013/14 $4^{12}$.

Enquanto os grandes e médios sojicultores estão inseridos nas dinâmicas locais integrando o tecido político regional, e os pequenos produtores são praticamente invisíveis, no caso dos assentados ocorre uma situação diferenciada. Todos conhecem a presença deste grupo, mas ele geralmente é estigmatizado e mal visto pelos diferentes segmentos da população urbana e rural, principalmente pelo fato de serem de diferentes regiões e terem vínculo com os movimentos sociais/sindicais - o que lhes agrega a conotação de pessoas contestadoras da ordem social e propensas ao conflito.

A participação dos assentados rurais no cultivo da soja ocorre, majoritariamente, por intermédio do PNPB, que tem como um dos objetivos a inclusão dos agricultores familiares nesta cadeia produtiva. Nesse sentido, a principal iniciativa construída foi o Selo Combustível Social ${ }^{13}$, que é recebido pelas empresas que apresentam um compromisso com a compra da matéria-prima da agricultura familiar (que inclui os assentados rurais). Para obter o Selo em Mato Grosso as indústrias precisam comprovar que no mínimo $15 \%$ da sua produção é abastecida por cultivos oriundos deste público (MDA, 2013).

Atualmente na região estudada a relação entre a empresa de biodiesel e o assentado é materializada com um contrato (que também é assinado pelo STR) para a entrega da soja. Neste esquema geralmente é a usina quem compra os insumos nas revendas locais e repassa aos assentados, além de oferecer assistência

\footnotetext{
${ }^{12}$ É importante salientar que essas ações são conduzidas de maneira ilegal, pois é proibido vender, arrendar, repassar, alugar ou fazer comércio de qualquer natureza com lote que integre algum assentamento da reforma agrária. Isso porque o trabalhador rural recebe apenas uma concessão para usar e explorar a parcela (INCRA, 2015).

${ }^{13}$ As empresas que possuem o Selo têm como principais vantagens a redução da carga tributária, o acesso a melhores condições de financiamento e a participação assegurada nos leilões públicos para venda do seu biodiesel (MDA, 2013). Esse cenário estimula que as usinas promovam a produção de soja junto aos agricultores familiares e assentados da reforma agrária.
} 
técnica (há um quadro permanente da própria empresa, mas com auxílio complementar da revenda). Pelos insumos e serviços o produtor irá pagar em soja no momento da colheita. O restante da soja colhida é vendido para a empresa de biodiesel, de modo que o preço pode ser pré-fixado (como faz grande parte dos sojicultores) ou variar conforme o valor do dia da entrega. Além desse valor, os assentados recebem um bônus de $\mathrm{R} \$ 1,20 / \mathrm{saca}$, por ser um produto destinado ao PNPB $^{14}$. Em alguns casos a empresa também media o acesso ao maquinário terceirizado, quando os produtores não dispõem.

Embora a maioria dos produtores tenha seus nomes no contrato de entrega de soja ao PNPB, a dinâmica tem funcionado de outra forma. Ao analisar a situação particular de um assentamento de Campo Verde, Beal (2010) aponta que em 2009 apenas seis assentados efetivamente produziam a oleaginosa, embora houvesse soja plantada na maioria dos lotes (70 no total). O que ocorre é que os "assentados mais fortes" (com mais experiência na agricultura, que se encontram mais capitalizados e detêm a posse de máquinas e implementos agrícolas) arrendam as áreas dos seus vizinhos. Apesar disso, a empresa de biodiesel faz um contrato individual em nome de cada um dos assentados (mesmo daqueles que têm seu lote arrendado para outro). Esse pacto é estratégico para a usina, que desta forma mantém o Selo Combustível Social e seus benefícios; para os assentados que arrendam seus lotes, pois recebem o valor do aluguel da terra e o bônus de $R \$ 1,20$ de cada saca entregue à empresa (esse valor não fica com quem produz a soja porque o pagamento vem em nome do titular do lote); e para o assentado arrendatário - que amplia a sua escala de produção, recebe incentivos da usina de biodiesel e fica isento da cobrança de contribuição social para o Fundo de Apoio ao Trabalhador Rural (Funrural) porque está incluído no PNPB ${ }^{15}$.

\section{Breves considerações sobre a diversidade de sojicultores}

A expansão da soja pelo centro-norte brasileiro uniformizou parte significativa das paisagens rurais formando espaços produtivos homogêneos e contínuos, ao mesmo tempo em que alterou o perfil dos produtores deste grão. Apesar das inegáveis transformações que têm afetado os sojicultores (mudanças tecnológicas, econômicas, comerciais, na gestão etc.), que apontam para uma agricultura globalizada e financeirizada, esta lógica vem sendo apropriada e articulada de

\footnotetext{
${ }^{14}$ Este "prêmio" é oriundo da indústria, que repassa parte dos seus benefícios por deter o Selo Combustível Social aos produtores da matéria-prima. O valor é definido em uma negociação que envolve as empresas de biodiesel e as entidades de representação da agricultura familiar do estado.

${ }^{15}$ Conforme o relato de um assentado que possui 50 hectares próprios e arrenda mais 250 ha de outros assentados, ele colhe em média 15 mil sacas de soja nos 300 hectares, o que significa que teria que pagar R\$30.000,00 de Funrural. Mas, como o grão das áreas arrendadas é destinado ao biodiesel, este produtor só contribui com o valor correspondente a 50 hectares ao Funrural, as quais estão cadastradas em seu nome.
} 
forma muito específica conforme as características de cada ator. Características estas que se alteram conforme a sua situação fundiária, lógica de organização e acumulação, origem socioespacial, poder econômico etc.

No Sudeste de Mato Grosso não se pode afirmar que exista um ator específico/único que predomine na produção da oleaginosa. Ainda que os meios técnicos para a produção da soja sejam semelhantes (ou até mesmo idênticos), existe uma grande diversidade de sojicultores cujas características não se restringem à dimensão fundiária, econômica e organizacional. Além desses elementos, as disparidades também envolvem os formatos das relações de troca com as empresas e as modalidades de negócio. Nesse sentido, a compra de insumos, por exemplo, é intermediada por diferentes atores - como o Estado (para produção de biodiesel), as revendas de insumos do próprio município, as cooperativas de produtores rurais, os Representantes Técnicos de Vendas (RTVs) e as empresas transnacionais (inclusive com a negociação construída em escala supranacional). Esta mesma complexidade e diversidade ocorrem na comercialização da soja, que é efetivada via exportação direta, empresas transnacionais com sede na região, firmas de capital nacional, revendas de insumos, usinas de biodiesel, dentre outras formas.

Cabe reforçar que a diferenciação dos produtores de soja construída neste trabalho está atrelada às próprias características do Sudeste Mato-Grossense. Dessa maneira, a trajetória de ocupação do território nas décadas de 1970 e 1980 tem uma influência importante, dado que os produtores - em maior medida sulistas - ainda ocupam posição de destaque na região e na estrutura social, política e econômica dos municípios. Ademais, é a propriedade dos meios de produção que predomina entre os estabelecimentos agropecuários, além da menor rotatividade dos produtores. A presença de assentados da reforma agrária também complexifica esse cenário. Ainda que os diferentes tipos possam ser encontrados em outras regiões, o peso deles sobre a produção de soja pode ser bastante diferenciado. Como exemplo pode-se citar a predominância de pequenos produtores rurais no sul do país (em grande parte articulados com as cooperativas) (WESZ JR, 2011) e a incidência mais marcante dos grandes grupos empresariais em Mapitoba acrônimo usado para identificar as áreas de Cerrado do Maranhão, Piaú, Tocantins e Bahia (FOLHA DE SÃO PAULO, 2012; VALOR ECONÔMICO, 2013).

A coexistência de diferentes perfis de produtores de soja no Sudeste MatoGrossense, apesar de contar com algumas ações cooperadas que passam especialmente pela esfera política das entidades de representação, não é harmônica. A principal tensão observada é entre médios produtores e grandes grupos (familiar e empresarial), pois esses últimos expandiram suas áreas agrícolas tanto pela compra quanto pelo arrendamento, o que inflacionou o preço da terra. Isso interfere diretamente no custo de produção dos demais produtores que arrendam áreas complementares. Além disso, os médios, pequenos e assentados da reforma agrária argumentam que sua atividade fomenta a econômica local, enquanto que os 
grandes grupos enfraquecem a base socioeconômica regional, pois as negociações não passam por esta escala. Ademais, existem algumas disputas que fogem do plano produtivo/ econômico, envolvendo reconhecimento e prestígio. A entrada do El Tejar, por exemplo - ainda que seja vista com desconfiança - questiona, em certa medida, o modelo de negócio e as capacidades dos produtores que estão a mais tempo na região.

Embora a maior parte da produção de soja esteja vinculada aos grandes grupos familiares, ao grupo empresarial e aos médios produtores, não se pode desconsiderar a presença de um amplo conjunto de atores que exercem esta atividade, mesmo em regiões marcadas pela sua imersão no cultivo de commodities e nas cadeias globais de valor ${ }^{16}$. Apesar das afirmações encontradas durante a pesquisa de campo, que indica ser "impossível cultivar soja em área inferior a 500 hectares" ou de que "os produtores com menos de mil hectares vão desaparecer em breve", o que se percebe é a sua resistência. Nessa direção, cabem novas pesquisas que compreendam os fatores condicionantes desta capacidade de sobrevivência e manutenção de alguns sujeitos neste mercado, apesar do contexto setorial desfavorável para eles.

\section{Bibliografia}

ALMEIDA, L. S. (2013) Gaúchos, festas e negócios: o agronegócio da soja no Meio-Norte mato-grossense. Tese (Doutorado em Sociologia e Antropologia) Universidade Federal do Rio de Janeiro. Rio de Janeiro.

AMEGHINO, E. A. (2012) De la percepción empírica a la conceptualización: elementos para pensar teóricamente la estructura social de las explotaciones agrarias pampeanas. In: AMEGHINO, E. A. et al. (orgs.) Estudios agrários y agroindustriales. Buenos Aires: Imago Mundi. pp. 3-66.

APROSOJA - Associação dos Produtores de Soja de Mato Grosso. (2011) Pesquisa mostra novo perfil do sojicultor. Disponível em: <http://www.aprosoja.com.br/noticia/pesquisa-mostra-novo-perfil-do-sojicultor/> Acessado em: 10 maio 2014.

ARBELETCHE, P.; CARBALlO, I. (2006) Sojización y concentración de la agricultura uruguaya. In: XXXIV Congreso de la Asociación Argentina de Economía

Agrícola

Córdoba. Anais...

Argentina.

\footnotetext{
${ }^{16}$ As cadeias globais de valor (Global Value Chain - GVC) referem-se a processos produtivos que acontecem cada vez mais em escala globalizada. O exemplo mais clássico é quando cada etapa da cadeia (fabricação dos insumos, produção agropecuária, beneficiamento, distribuição e consumo) é efetivada em um país distinto. Para uma análise mais detalhada, consultar Gereffi e Korzeniewicz (1994), Gereffi, Humphrey e Sturgeon (2005), entre outros.
} 
BEAL, S. G. (2010) Pequena produção rural familiar e o selo social: Assentamento "28 de outubro" Campo Verde/MT. Dissertação (Mestrado em Geografia) - Universidade Federal de Mato Grosso. Cuiabá. BERNARDES, J. A. (2005) Circuitos espaciais da produção na fronteira agrícola moderna: BR-163 mato-grossense. In: BERNARDES, J. A.; FREIRE FILHO, O. de L. (orgs.) Geografia da soja BR-163: fronteiras em mutação. Rio de Janeiro: Arquimedes. pp. 13-37.

BUHLER, E. A.; OLIVEIRA, V. L. (2012) Agricultura Empresarial: novidades e desafios para a pesquisa sobre o rural. In: Encontro Nacional de Geografia Agrária. Anais..., Uberlândia-MG: UFO/LAGEA.

CONAB - Companhia Nacional de Abastecimento. (2014) Série Histórica de Produção. Disponível em: <http://www.conab.gov.br> Acessado em: 25 jun. 2014. DATALUTA - Banco de Dados da Luta Pela Terra. (2012) Mato Grosso: Relatório 2011. Cuiabá/MT.

EXAME. (2013) A agropecuária vive uma fase exuberante e empurra a economia. Disponível em: http://exame.abril.com.br/revistaexame/edicoes/1053/noticias/eles-salvam-a-lavoura. Acessado em: 09 fev. 2014.

FERNÁNDEZ, A. J. C. (2007) Do Cerrado à Amazônia: as estruturas sociais da economia da soja em Mato Grosso. Tese (Doutorado em Desenvolvimento Rural) Universidade Federal do Rio Grande do Sul. Porto Alegre.

FOLHA DE SÃO PAULO. (2012) Grandes grupos agrícolas devem dominar a produção na região de Mapitoba. Disponível em: http://www1.folha.uol.com.br/mercado/2012/12/1205555-grandes-gruposagricolas-devem-dominar-a-producao-na-regiao-de-mapitoba. Acessado em: 18 fev. 2015.

GEREFFI, G.; HUMPHREY, J.; STURGEON, T. (2005) The governance of global value chain: an analytic framework. Review of International Political Economy, v. $12, \mathrm{n}^{\mathrm{o}} 1$. pp.78-104.

GEREFFI, G.; KORZENIEWICZ, M. (eds.). (1994) Commodity chains and global capitalism. Westport: Praeger.

GRAS, C. (2013) Expansión agrícola y agricultura empresarial: el caso argentino. Revista de Ciencias Sociales, v. 26, nº 32, pp. 73-92.

(2012) Los empresarios de la soja: cambios y continuidades en la fisonomía y composición interna de las empresas agropecuarias. Mundo Agrario, v. $12, n^{\circ} 24$. pp. 1-32.

GROSSO, S. et al. (2010) Impactos de los "pools de siembra" en la estructura social agraria. Una aproximación a las transformaciones en los espacios centrales de la Provincia de Santa Fe - Argentina. Revista de Estudios Regionales y Mercado del Trabajo, $n^{\circ}$ 6. pp. 115-138.

GUIBERT, M. et al. (2011) De Argentina a Uruguay: espacios y actores en una nueva lógica de producción agrícola. Pampa, nº 7. pp. 13-88. 
GUIBERT, M.; BUHLER, E. A. (2013) El recurso suelo en las lógica productivas de las agriculturas empresariales en Argentina y en Brasil. In: XXXI International Congress of the Latin American Studies Association (LASA). Anais...Washington, DC.

HEREDIA, B. M. A.; PALMEIRA, M.; LEITE, S. P. (2010) Sociedade e Economia do Agronegócio. Revista Brasileira de Ciências Sociais, v. 25. pp. 159176.

HERNÁNDEZ, V.; MUZI, M. E.; RIGLOS, M. F. F. (2013) Figuras socioproductivas de la ruralidad globalizada. In: GRAS, C.; HERNÁNDEZ, V. (eds.) El agro como negócio: produción, sociedad y territórios en la globalización. Buenos Aires: Biblios. pp. 151-170.

IBGE - Instituto Brasileiro de Economia e Estatística. (2014) Banco de dados agregados. Disponível em: <http://www.sidra.ibge.gov.br>. Acessado em: 22 jan. 2014.

IBGE - Instituto Brasileiro de Economia e Estatística. (2013) Produção Agrícola Municipal. Disponível em: http://www.sidra.ibge.gov.br/bda/pesquisas/pam/. Acessado em: 30 jan. 2014.

(2012) Censos Agropecuários. Disponível em: < http://www.sidra.ibge.gov.br/bda/pesquisas/ca/>. Acessado em: 23 jan. 2014. INCRA - Instituto Nacional de Colonização e Reforma Agrária. (2015) Reforma agrária. Disponível em: < http://www.incra.gov.br/reforma_agraria> Acessado em: 15 jun. 2015.

LEITE, S. P. (1998) Inserção internacional e financiamento da agricultura brasileira (1980-1996). Tese (Doutorado em Economia) - Universidade Estadual de Campinas. Campinas.

MDA - Ministério do Desenvolvimento Agrário. (2013) PNPB. Disponível em: <http://portal.mda.gov.br/portal/saf/programas/biodiesel> Acessado em: $12 \mathrm{fev}$. 2013.

MORENO, G. (2005) Políticas e estratégia de ocupação. In: MORENO, G.; HIGA, T. C. S. (orgs.) Geografia de Mato Grosso: Território, sociedade, ambiente. Cuiabá: Entrelinhas. pp. 34-51.

OYHANTÇABAL, G.; NARBONDO, I. (2011) Radiografia del agronegocio sojero: descripción de los principales atores y los impactos socioeconómicos en Uruguay. Montevideu: Redes.

PÉREZ LUNA, M. (2007) No todo grano que brilla es oro: un análisis de la soya en Bolivia. La Paz: CEDLA.

SECEX - Secretaria de Comércio Exterior. (2014) Indicadores e Estatísticas de Comércio Exterior. Disponível em: http://www2.desenvolvimento.gov.br/sitio/secex. Acessado em: 14 jan. 2014. SOUAGRO. (2011) A nova geração do agro. Disponível em: <http://souagro.com.br/a-nova-geracao-do-agro> Acessado em: 13 jul. 2013. 
URIOSTE, M. (2011) Concentración y extranjerización de la tierra en Bolivia. Fundación TIERRA: La Paz, Bolivia.

USDA - Departamento de Agricultura dos Estados Unidos. (2014) Data and Statistics. Disponível em: <http://www.usda.gov/wps/portal/usda/>. Acessado em: 06 mar. 2014.

VALOR ECONÔMICO. (2013) Dez grupos têm um terço da nova fronteira da soja. Disponível em:<http://www.valor.com.br/empresas/3067336/dez-grupos-temum-terco-da-nova-fronteira-da-soja>. Acessado em: 26 mar. 2015.

WESZ JR, V. J. (2011) Dinâmicas e estratégias das agroindústrias de soja no Brasil. Rio de Janeiro: E-papers.

. (2014) O mercado da soja e as relações de troca entre produtores rurais e empresas no Sudeste de Mato Grosso (Brasil). Tese (Doutorado em Ciências Sociais) - Universidade Federal Rural do Rio de Janeiro. Rio de Janeiro. 